\title{
Evasão na educação a distância: pontos e contrapontos à problemática
}

\author{
Evasion in distance education: points and contrapts to problem
}

\author{
Lilian Soares Alves Branco ${ }^{1}$
}

${ }^{1}$ Universidade La Salle | Faculdade de Educação | Departamento de ${ }^{1}$ Pós-Graduação em Educação |

Canoas | RS | Brasil. Contato: lilian.sab@gmail.com. ORCID: http://orcid.org/0000-0002-6629-6006

\section{Elaine Conte ${ }^{2}$}

${ }^{2}$ Universidade La Salle | Faculdade de Educação | Departamento de Pós-Graduação em Educação |

Canoas | RS | Brasil. Contato: elaine.conte@ unilasalle.edu.br. ORCID: http://orcid.org/0000-0002-

$\underline{0204-0757}$

\author{
Adilson Cristiano Habowski ${ }^{3}$ \\ ${ }^{3}$ Universidade La Salle | Faculdade de Educação | Departamento de Pós-Graduação em Educação | \\ Canoas | RS | Brasil. Contato: adilsonhabowski@ hotmail.com. ORCID: http://orcid.org/0000-0002- \\ $\underline{5378-7981}$
}

Resumo: O estudo visa traçar um panorama das causas da evasão na educação a distância, discutindo os (contra)pontos e jogando luzes ao problema. Embora existam muitos estudos e discursos afinados sobre as causas da evasão, percebemos um distanciamento por parte das instituições formadoras em relação aos problemas da evasão, o que gera uma diminuição ou isenção de responsabilidades, tendo em vista a tendência em atribuir suas causas a dimensões psicológicas do estudante ou a (in)comunicabilidade entre os sujeitos participantes ou ainda às (des)continuidades ordenadas normativamente. O esforço dessa pesquisa consiste em dar visibilidade ao conjunto de dissertações e teses produzidas sobre a evasão na EaD. Trata-se de mapear na Biblioteca Digital Brasileira de Teses e Dissertações estas produções com os descritores Evasão EaD, por meio de uma busca avançada, considerando o período de publicação de 2007 a 2017. Acerca dessa temática, obtivemos setenta e dois resultados, dos quais fizeram parte do corpus investigativo de produção de dados sessenta e oito trabalhos. Compreende-se que apesar da EaD ser avaliada como um modelo de gestão propício às demandas sociais ela recebe forte influência de interesses de mercado, o que exige reavaliações constantes para um processo efetivo de (re)construção de conhecimentos e metodologias, contribuindo, também, para a diminuição dos índices da evasão (tensão inclusão/exclusão) na EaD. O estudo pontuou vários fatores comuns à evasão, apresentando contrapontos, no sentido de utilizar meios tradicionais de forma virtualizada, e propostas de melhoria nos processos via $\mathrm{EaD}$, considerando os limites de estudar a distância, a necessidade de não confundir flexibilidade com facilidade para avaliação dos estudantes.

Palavras-chave: Evasão. Educação a distância. Pontos. Contrapontos.

Abstract: The study aims to outline the causes of avoidance in distance education, discussing the (Counter) points and throwing light on the problem. Although there are many studies and refined discourses on the causes of evasion, we perceive a distancing by training institutions from the problems of evasion, which leads to a decrease or lack of responsibility, given the tendency to attribute their causes to psychological dimensions of the student or the (in) communicability between the subjects involved or even the normatively ordered (dis) continuities. The effort of this research consists in giving visibility to the set of dissertations and theses produced on the evasion in the EaD. It is a question of mapping these productions with the descriptors Evasion $\mathrm{EaD}$ in the Brazilian Digital Library of Theses and Dissertations, by means of an advanced search, considering the period of publication from 2007 to 2017. About this theme, we obtained seventy-two results, of which sixty-eight papers were part of the investigative corpus of data production. It is understood that although $\mathrm{EaD}$ is evaluated as a management model conducive to social demands, it is strongly influenced by market interests, which requires constant re-evaluations for an effective process of (re) construction of knowledge and methodologies, to reduce the rates of evasion (inclusion / exclusion strain) in the EaD. The study pointed out several common factors to avoidance, presenting counterpoints in the sense of using traditional means in a virtualized way, and proposals for improvement in processes via distance learning, considering the limits of studying distance, the need not to confuse flexibility with ease for evaluation of students.

Keywords: Evasion. Distance education. Points. Counterpoints.

- Recebido em: 2 de abril de 2019 - Aprovado em: 27 de fevereiro de 2020

DOI: http://dx.doi.org/ 10.1590/S1414-40772020000100008

Este é um artigo publicado em acesso aberto sob uma licença Creative Commons

https://creativecommons.org/licenses/by-nc/4.0/

Avaliação, Campinas; Sorocaba, SP, v. 25, n. 01, p. 132-154, mar. 2020 


\section{Considerações iniciais}

Há uma taxa média de evasão nos cursos $\mathrm{EaD}$ que, segundo Oliveira, Oesterreich e Almeida (2018), é de 26,3\%, sendo que $85 \%$ dos estudantes evadem no início do curso e, em alguns casos, a taxa de evasão é muito maior. Em vez da conformidade com esses dados, é necessário falar em evasão para compreender a problemática que parece comum aos cenários educativos de EaD e para propor melhorias, tendo em vista aproximar/fidelizar o estudante e modificar esse quadro. Torna-se urgente uma reavaliação das circunstâncias que leva e provoca no estudante a evasão dos estudos. Sabemos que o fenômeno da evasão ocorre em todas as modalidades de ensino - presencial, semipresencial e a distância - seja ela pública ou privada. Porém, na $\mathrm{EaD}$ requer um cuidado maior, por se constituir em uma dinâmica mediada pelas tecnologias digitais o que fragiliza os vínculos estabelecidos no contato materializado na performance expressiva (entonação da palavra, gesto e corpo) do estudante.

A partir de diferentes contextos da realidade educacional, lançamos um olhar investigativo para mapear as dissertações e teses produzidas e que estão disponibilizadas em um catálogo nacional na Biblioteca Digital Brasileira de Teses e Dissertações (BDTD), do Instituto Brasileiro de Informação Científica e Tecnológica (IBICT). Vale admitir que para examinar as produções de um campo de pesquisa é preciso investigar as dissertações e teses, pois permitem perceber o que está acontecendo no momento, de modo a contribuir com a racionalidade pedagógica e uso desses conhecimentos, oferecendo condições para um exercício compreensivo e reflexivo dos horizontes de experiência da questão (ALMEIDA JUNIOR et al., 2005). Na tentativa de avaliar as questões pedagógicas atinentes à evasão na EaD, propomos a seguinte questão norteadora: Quais as perspectivas apresentadas nos bancos de teses e dissertações sobre o problema da evasão em cursos de EaD e quais as alternativas viáveis à (re/auto)avaliação das práticas para minimizar tal fenômeno? Para essa coleta inicial, utilizamos como descritor de busca: Evasão EaD, inseridos juntos na categoria busca avançada, considerando o período de 2007 a 2017, para compreender e dar visibilidade às produções e debates recentes acerca da temática nos programas de pós-graduação do país.

Inicialmente, elegemos os resumos como categoria de análise das teses, mas, na tentativa de aprofundar alguns elementos das produções, partimos para um reexame de algumas partes das teses, mais detidamente, a introdução e as conclusões. Com esse movimento de reconhecimento de experiências foi possível traçar um panorama que serviu para repensar as discussões sobre as tecnologias nesses contextos de EaD. A pesquisa descreve cada tese mapeada, apontando os principais desafios, lacunas e possibilidades, em termos de 
convergências argumentativas, para compreender a dimensão desse mundo complexo, multifacetado e paradoxal das múltiplas formas de linguagem da $\mathrm{EaD}$.

O caminho interpretativo ao problema será traçado pelas vias hermenêuticas de (re)construção dos conhecimentos, possibilitando a compreensão dos discursos sobre EaD, em termos de validação e revisão das experiências mapeadas, nas dimensões dos seus significados sociais e horizontes culturais. A pesquisa de cunho teórico e conceitual será baseada na amostra por seleção de dados realizada no repositório digital da BDTD, bem como em livros e artigos publicados em periódicos do campo da educação. A abordagem hermenêutica nos permite compreender as contradições presentes nos discursos da $\mathrm{EaD}$, como uma possibilidade de análise das aproximações em torno dos diagnósticos e das causas da evasão, visto que todo saber é falível e propício à verificação e revisão. Tal abordagem pressupõe a atitude de olhar os textos já publicados, a fim de entregar-se ao outro, ao (con)texto, ao diálogo, ao mundo de significados, na busca de novos sentidos à educação. Heidegger (1995, p. 204) corrobora com a ideia ao afirmar que interpretar "[...] não é tomar conhecimento do que se compreendeu, mas elaborar as possibilidades projetadas na compreensão". Os resultados alcançados remetem a um diagnóstico projetivo dos processos e práticas de $\mathrm{EaD}$, bem como revelam estratégias para reversão da evasão nos processos de educar.

\section{Conceitos sobre evasão}

A evasão é a interrupção do curso por parte do estudante, independente da etapa que este se encontra no curso, seja no início, no percurso ou no final. De fato, se ocorrer a desistência nesse processo podemos considerar que o estudante evadiu do curso. Conforme Santos et al. (2008, p. 2), evasão é “[...] a desistência definitiva do estudante em qualquer etapa do curso e a mesma pode ser considerada como um fator frequente em cursos a distância”. Para Gaioso (2005), Kira (1998), Baggi e Lopes (2011), a evasão também se dá quando ocorre a perda do estudante antes de concluir o curso. Por sua vez, de acordo com o posicionamento do Ministério da Educação, o conceito adotado é "a saída definitiva do curso de origem sem conclusão, ou a diferença entre ingressantes e concluintes" (BRASIL, 1996, p. 19).

Outros pesquisadores distinguem os conceitos envolvendo a evasão, Favero (2006) também considera a evasão como a desistência do curso, incluindo até os que nunca estiveram ou se manifestaram no decorrer do curso para seus professores, tutores e colegas. Nesse contexto de discussão, há uma diferenciação entre evasão por desistência do curso e evasão por reopção de curso, sendo que a primeira deve ser avaliada separadamente, pois na segunda 
observa-se ainda uma mobilidade acadêmica. Na evasão por desistência existe o risco de o estudante não retornar ao curso, contribuindo para a exclusão/abandono. No entanto, ambas as situações devem ser analisadas como uma oportunidade de reversão do problema. Para uma melhor compreensão dos diferentes conceitos e percepções sobre evasão, o quadro 1 na sequência apresenta uma síntese das perspectivas apresentadas pelos autores citados.

\section{Quadro 1 - Síntese de algumas perspectivas de evasão}

\begin{tabular}{|c|c|c|}
\hline \multicolumn{3}{|c|}{ Conceitos de Evasão } \\
\hline Autor & Evasão & Observação \\
\hline SANTOS (2008) & É a desistência definitiva do curso. & Independente da etapa. \\
\hline GAIOSO (2005) & Pode ocorrer antes de concluir o curso. & Refere-se à perda do estudante. \\
\hline KIRA (1998) & $\begin{array}{l}\text { Refere-se ao fato de não concluir o } \\
\text { curso. }\end{array}$ & Ressalta a perda do estudante. \\
\hline $\begin{array}{l}\text { BAGGI; LOPES } \\
\text { (2011) }\end{array}$ & Ressalta a ideia de não concluir o curso. & Ressalta a perda do estudante em um curso. \\
\hline BRASIL (1997) & É a saída do curso de origem. & $\begin{array}{l}\text { Desconsidera a mobilidade acadêmica } \\
\text { (troca de curso). }\end{array}$ \\
\hline FAVERO (2006) & É a desistência do curso. & $\begin{array}{l}\text { Considera os que realizaram e os que nunca } \\
\text { participaram das atividades propostas. }\end{array}$ \\
\hline VARGAS (2007) & $\begin{array}{l}\text { Considera o período de início e a saída } \\
\text { do curso. }\end{array}$ & $\begin{array}{l}\text { Busca identificar o período que ocorreu a } \\
\text { evasão. }\end{array}$ \\
\hline $\begin{array}{l}\text { POLYDORO } \\
(2000)\end{array}$ & $\begin{array}{l}\text { Considera o abandono no curso e no } \\
\text { sistema universitário. }\end{array}$ & $\begin{array}{l}\text { Considera dois marcos - abandono no } \\
\text { curso e no sistema universitário - } \\
\text { relacionados à desistência definitiva dos } \\
\text { estudos e evasão. }\end{array}$ \\
\hline $\begin{array}{l}\text { CARDOSO } \\
(2008)\end{array}$ & $\begin{array}{l}\text { Mobilidade do estudante para outro } \\
\text { curso e a desistência do curso. }\end{array}$ & $\begin{array}{l}\text { A troca de curso já é considerada uma } \\
\text { evasão. }\end{array}$ \\
\hline
\end{tabular}

Fonte: Elaborado pelos autores (2019).

A maioria dos autores analisados relaciona a evasão com a desistência/abandono do curso - seja o curso de origem ou não e, novamente, ressaltam como exclusiva responsabilidade do estudante, diminuindo a corresponsabilidade ou isentando a gestão institucional. Se a evasão está relacionada à exclusão, a instituição de ensino precisa criar mecanismos de aproveitamento e canais de comunicação que direcionem a permanência do estudante. A questão da mobilidade acadêmica é compreendida como a migração e transferência do estudante para outro curso, não como abandono/desistência dos estudos, mas como uma tentativa de busca de identificação com a formação profissional e área de interesse na construção da trajetória acadêmica como contraponto à evasão.

\section{Diagnóstico das causas da evasão na EaD}

Com o crescimento da oferta de cursos de $\mathrm{EaD}$, torna-se fundamental observar a mobilidade acadêmica dos estudantes, destacando que independentemente se houve a evasão 
dos estudos, o trancamento ou a evasão do curso, podemos identificar diferentes facetas de análise para este fenômeno. A evasão observada de fora pode ser vista como um fracasso, por conta do estudante não ter concluído ou ter trocado de curso. Porém, também pode ser um fator positivo, visto que a meta do estudante não seria atingida se permanecesse atrelado a um curso indesejado e desinteressante profissionalmente, demonstrando um amadurecimento intelectual e emocional da pessoa. A mobilidade acadêmica seria uma forma de reduzir os índices de evasão, pois mesmo que o estudante não permaneça no curso de origem, ele continua estudando e matriculado, independentemente do curso. Para não adotarmos uma visão reducionista do fenômeno da evasão, salientamos que é preciso considerar os enfoques psicológicos, sociológicos, econômicos, organizacionais e interacionistas da questão, tal como proposto na figura 1.

Figura 1 - Enfoques da Evasão na EaD

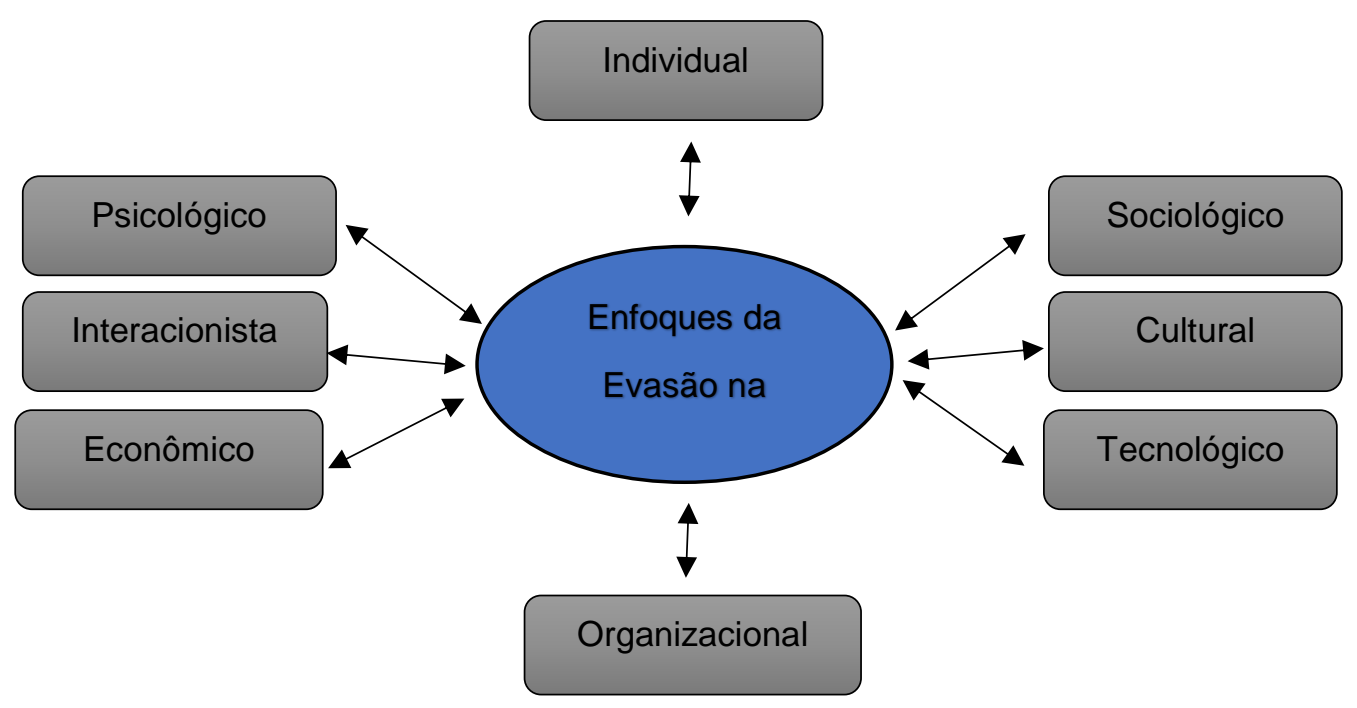

Fonte: Elaborado pelos autores (2019).

Ethington (1990) destaca que o abandono se dá pela falta de clareza das intenções do estudante. Para os autores Andriola, Andriola e Moura (2006, p. 374), "a desinformação acerca do curso e da carreira superior escolhida é um fator responsável pela evasão discente", tendo esse um enfoque psicológico, destacando, adicionalmente, as intenções, informações a respeito do curso e as expectativas do estudante. Já a abordagem sociológica considera a integração acadêmica, pois, segundo Tinto (1975), a evasão se dá por falta de inclusão acadêmica com a instituição. O estudante chega à universidade com suas intenções e objetivos predefinidos, porém, no decorrer do curso o estudante vai redefinindo suas intenções para a permanência ou evasão do curso, cuja inclusão vai depender da gestão comunicacional, via instituição, fortalecida por meio da interação acadêmica. Cabrera, Bethencourt, Pérez e Afonso (2006) 
desenvolvem a ideia de que a permanência se dá quando os estudantes percebem o benefício social e econômico em relação aos seus estudos, possibilitando a participação de atividades extraclasses.

Sob a perspectiva de Bean e Metzner (1985), a decisão de evadir ou persistir no curso é um fator psicossocial, onde as opiniões influenciam as atitudes, ou seja, a aprovação da família, a qualidade oferecida pela instituição e o encorajamento dos amigos, tudo isso motiva a tomada de decisão, respondendo aos anseios individuais. Para Peixoto, Braga e Bogutchi (2003), a evasão está relacionada ao desempenho acadêmico, mais especificamente, ao rendimento nos primeiros períodos de curso, e não está relacionada diretamente à questão socioeconômica e cultural do estudante. Após a revisão de Morosini et al. (2012), são descritos dados que podem resultar na evasão, menciona aspectos tais como: a insatisfação com o curso, a falta de aconselhamento quanto aos programas de estudo e os conflitos quanto à escolha profissional.

É difícil definir um momento exato em que ocorre a evasão dos estudantes, embora esse fator é especialmente importante para o acompanhamento das suas causas. Sem sombra de dúvidas, muitos desses motivos de abandono estão relacionados à falta de interação humana com as tecnologias digitais e com os sujeitos participantes, envolvendo um problema social que abarca o aspecto pedagógico, bem como a falta de apoio, acolhimento e incentivo por parte das instituições de ensino. Dessa forma, alguns se matriculam e nem chegam a iniciar o curso, por não entenderem a metodologia de ensino, apresentando dificuldades de participar das atividades propostas, sentindo-se perdidos nesse ambiente de ensino, o que compromete o desenvolvimento dos processos de aprendizagem. Para uma melhor compreensão da produção dos dados envoltos nesta problemática, expomos os dados apresentados pelo Instituto Nacional de Estudos e Pesquisas Educacionais Anísio Teixeira (INEP), através do Censo da Educação Superior no Brasil, índices que contemplam o número de matriculados, comparando com os índices de concluintes, considerando a amostra do ano de 2015. Na sequência, podemos verificar o número de matrículas em diferentes modalidades de ensino, a nível de Brasil em esfera pública e privada. Também é possível observar o maior número de matrículas pertencentes às instituições privadas, na seguinte ordem de matrículas por modalidade: $1^{\circ}$ Bacharelado, $2^{\circ}$ - Licenciaturas e $3^{\circ}$ - Tecnológicos. 


\section{Quadro 2 - Matrículas em Cursos de Graduação Presenciais e a Distância}

\begin{tabular}{|c|c|c|c|c|c|}
\hline \multirow{3}{*}{$\begin{array}{l}\text { Unidade da Federação / } \\
\text { Categoria Administrativa }\end{array}$} & \multicolumn{5}{|c|}{ Matrículas em Cursos de Graduação Presenciais e a Distância-2015 } \\
\hline & \multicolumn{5}{|c|}{\begin{tabular}{|c|} 
Total Geral \\
\end{tabular}} \\
\hline & Total & Bacharelado & Licenciatura & Tecnólogo & Não Aplicável \\
\hline Brasil & 8.027 .297 & 5.516 .151 & 1.471 .930 & 1.010 .142 & 29.074 \\
\hline Pública & 1.952 .145 & 1.195 .020 & 578.997 & 149.209 & 28.919 \\
\hline Federal & 1.214 .635 & 800.417 & 323.295 & 68.862 & 22.061 \\
\hline Estadual & 618.633 & 301.873 & 233.222 & 76.699 & 6.839 \\
\hline Municipal & 118.877 & 92.730 & 22.480 & 3.648 & 19 \\
\hline Privada & 6.075 .152 & 4.321 .131 & 892.933 & 860.933 & 155 \\
\hline
\end{tabular}

Fonte: Adaptado pelos autores (INEP, 2018).

A partir do número de matriculados, podemos analisar o número de concluintes, sendo possível observar que o número de concluintes do ensino superior, em suas diferentes categorias, é muito inferior ao número de matrículas do mesmo ano. Na sequência, são apresentados os gráficos com o percentual de concluintes de cada uma das categorias de ensino. O que nos leva a pensar o quanto ainda precisamos debater acerca dos parâmetros que impactam na evasão, para que possamos reavaliar os processos e práticas educativas, no sentido de lançar luz ao problema e indicar possíveis alternativas para reverter esses índices.

\section{Quadro 3 - Número de Concluintes em Cursos de Graduação Presenciais e a Distância}

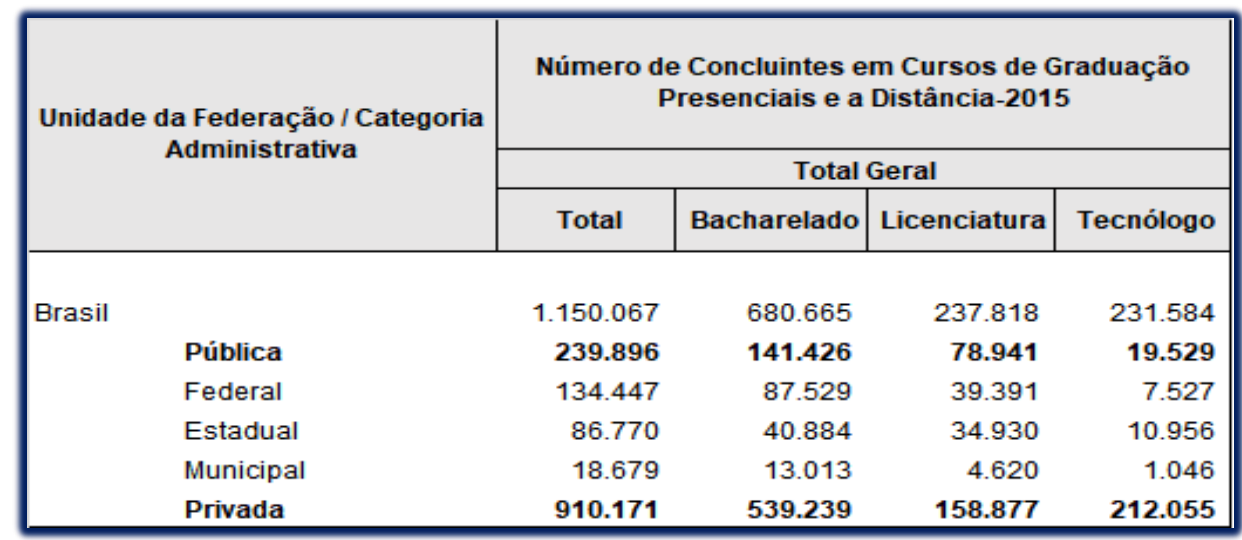

Fonte: Adaptado pelos autores (INEP, 2018).

Observamos nos quadros um maior número de concluintes em licenciatura no ensino público, enquanto que no ensino privado, essa modalidade fica em terceira opção entre os concluintes. Já na modalidade de tecnólogo ocorre uma diferenciação, no ensino público esta modalidade está em terceira opção entre os concluintes, enquanto no ensino privado esta modalidade está na segunda opção, ficando à frente das licenciaturas. Dessas diferentes situações de matrículas - trancadas, desvinculadas, transferidas e falecidos, podemos ver que a 
evasão se faz presente, pois o fato desta matrícula estar trancada, já significa que houve uma desistência em determinado momento do curso. O número elevado de matrículas trancadas, seja por desmotivação ou outro fator, é preocupante, tanto na instituição pública quanto na privada, o que nos leva a questionar se está sendo proposta alguma política ou prática de reavaliação e reversão destes números.

Esses apontadores comprovam que a procura de $\mathrm{EaD}$ existe, porém, a conclusão dos cursos é que tem apresentado limitações e percalços. Assim, melhorar esse cenário e superar esses índices requer pensar na qualidade do ensino oferecida no ensino a distância, bem como na ausência e negligência de gestão dos processos comunicativos nos processos educativos da EaD. Por meio dos índices apresentados, percebemos o quanto ainda precisamos dar visibilidade ao problema da evasão no ensino superior a distância, para que o afastamento e a desistência dos estudantes não seja um dado constante nas estatísticas dos cursos. Além disso, rastrear o momento do trancamento é de suma importância para que possamos analisar em que momento ocorreu a dificuldade, seja no início, no decorrer ou até no final do curso, porque dependendo do momento em que ocorreu a evasão, as políticas e as estratégicas adotadas para resolver a situação-problema devem ser diferenciadas.

Quando analisamos esses índices de matriculados e concluintes, percebemos grandes fragilidades da educação, começando pela organização didático-pedagógica do curso, que inclui: os egressos, os objetivos, a metodologia, matriz e conteúdos curriculares programados, o processo de avaliação da aprendizagem, alfabetização e letramento digital, integração do estudante à prática educativa, bem como a inclusão e o engajamento dos sistemas de ensino e formação dos professores, formação esta que tende a ser reproduzida, ou seja, reporta às práticas tradicionais de ensino e não às realidades diversas da sala de aula. Tudo leva a crer que não se trata apenas de desenvolver novos dispositivos e inovações tecnológicas, mas de saber aprender a ressignificar e a integrar suas potencialidades a favor da educação, de forma significativa para a aprendizagem do estudante, nas dimensões dos seus significados sociais e horizontes culturais.

\section{Os achados...}

Ao considerar a pesquisa realizada durante o ano de 2018, na BDTD, com o descritor “evasão na educação a distância”, no período de 2007 a 2017, obtivemos 75 trabalhos. Destes, foram considerados 72 produtos por apresentarem elementos referentes às causas da evasão. 
Dentre as muitas produções coletadas (75 trabalhos), três ${ }^{1}$ não estavam disponíveis para leitura, constavam na relação de busca, mas estavam indisponíveis para consulta pública. Por meio desse diagnóstico inicial, partimos para a análise dos 72 trabalhos mapeados, compostos por 54 dissertações e 18 teses. Ainda, dos 72 trabalhos, quatro apresentavam evasão nas palavras-chave, porém, não apresentavam elementos de discussão sobre evasão na EaD. Nessa perspectiva, as pesquisas excluídas da análise são os seguintes: 1. Capacitação por ensino à distância de agentes de saúde na prevenção de doenças parasitárias; 2. As trajetórias escolares de alunos com necessidades educacionais especiais no Instituto Federal do Paraná: uma análise dos indicadores do censo escolar; 3. Evasão em curso de especialização multiprofissional em saúde da família: comparação entre modalidade a distância versus presencial; 4. Dois ensaios sobre aspectos recentes do ensino superior brasileiro. Com isso, nosso corpus investigativo está composto por 68 trabalhos, que dão conta dos objetivos da pesquisa em tela.

Cabe ressaltar que embora anteriormente foi apresentada a evasão no ensino superior dos cursos de licenciatura (item 3.4), a fim de embasar a modalidade de EaD em que a evasão está presente, agora ampliamos o debate acerca da evasão, considerando todos os níveis e modalidades de ensino e as áreas de conhecimento, tendo em vista os resultados das buscas, conforme o respectivo período. A partir desse corpus investigativo, podemos identificar a origem dos trabalhos apresentados e sua distribuição e um olhar panorâmico das instituições que mais realizaram pesquisas na área. Em produção na área, destaca-se, em primeiro lugar, a Universidade de Brasília (UnB), seguida pela Universidade de Santa Catarina (UFSC) e pela Universidade do Vale do Rio dos Sinos (UNISINOS), conforme o quadro a seguir.

\footnotetext{
${ }^{1}$ Os seguintes trabalhos intitulados a seguir não fizeram parte da análise: 1. Estratégias e institucionalização no enfrentamento da evasão escolar no ensino a distância à luz da adaptação estratégica em uma instituição de ensino superior do estado do Ceará; 2. E-v@ são em um curso de aperfeiçoamento on-line em saúde; 3. Evasão: análise da realidade do curso de graduação em administração a distância da Universidade Federal de Santa Catarina.
} 
Quadro 4 - Origem/quantidade de trabalhos por instituição

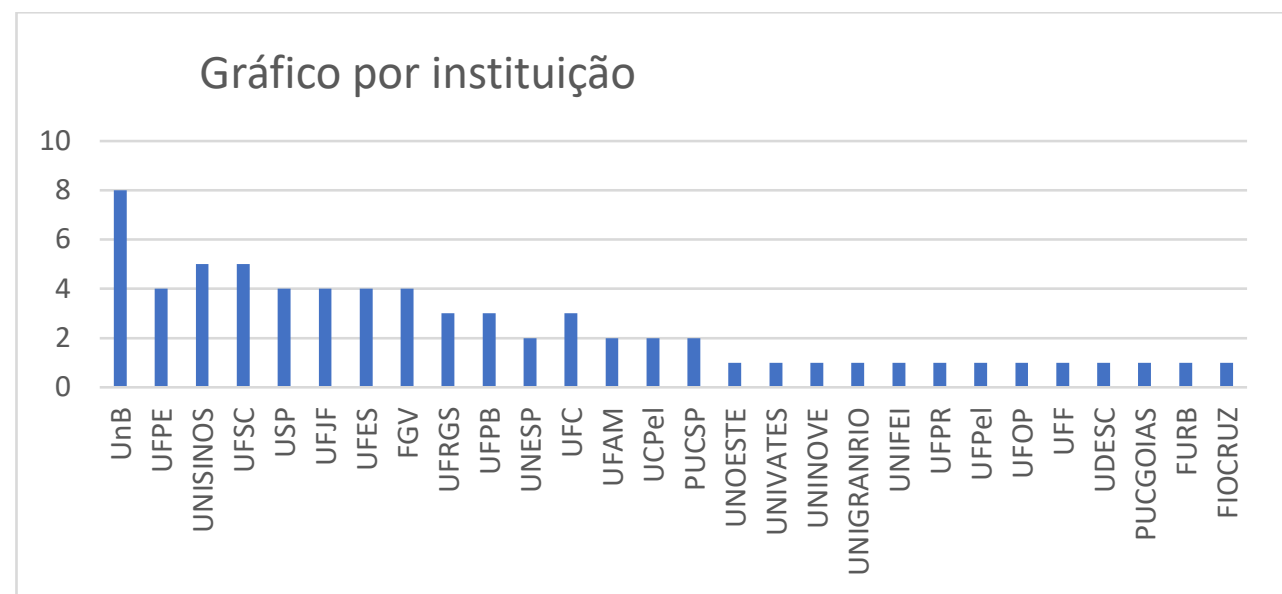

Fonte: Elaborado pelos autores (2019).

Na figura supracitada, é possível observar as instituições que mais realizaram pesquisas sobre a evasão na educação, já no quadro que segue, podemos verificar que apesar de alguns anos com poucas pesquisas ou com quedas no número de trabalhos publicados sobre as questões de evasão, de um modo geral, em 2017 quase duplicou o número das produções discentes sobre a temática da evasão na $\mathrm{EaD}$.

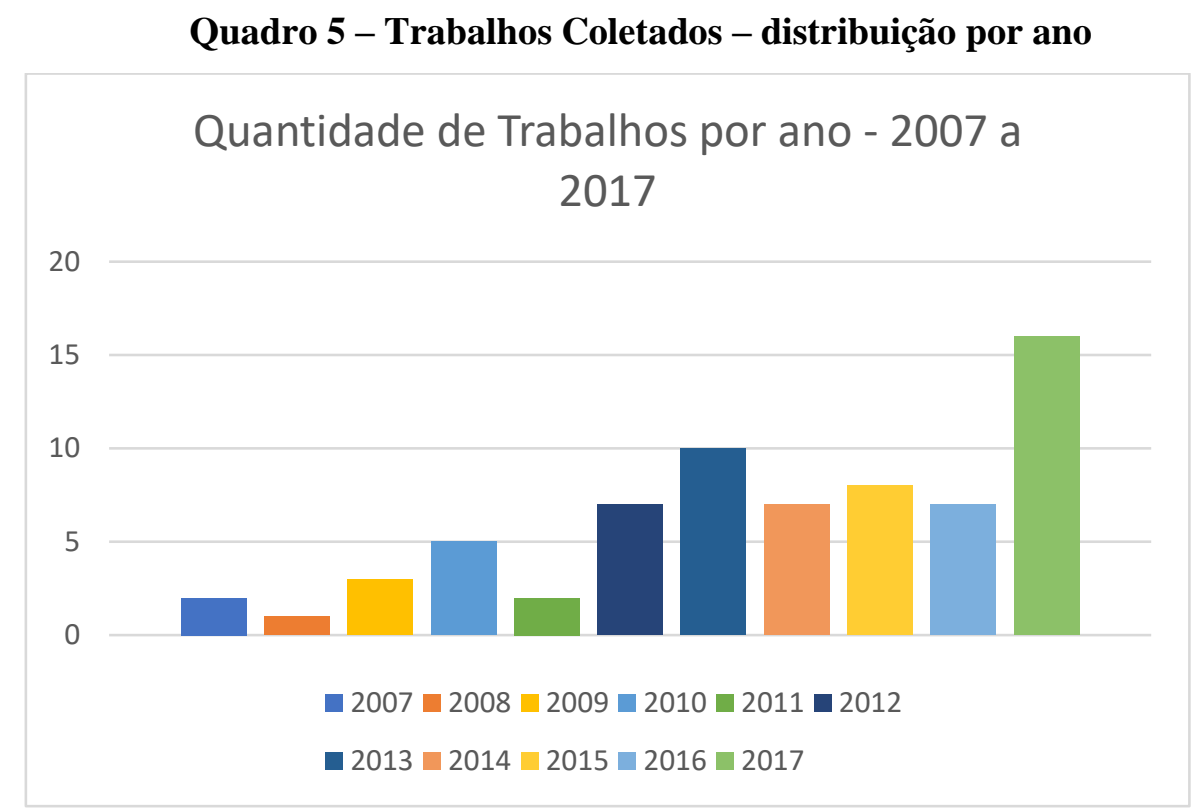

Fonte: Elaborado pelos autores (2019).

Contudo, o ano de 2017 apresentou um percentual de $23 \%$ do total de trabalhos realizados, 2013 correspondeu a 16\% e os anos de 2012, 2014 e 2016 um percentual de 10\%. Frente a isso, destacamos que apesar das oscilações tais dados revelam um aumento 
significativo de trabalhos nos últimos cinco anos. A partir da coleta realizada, pontuamos as palavras-chave (Quadro 6) e o percentual das palavras-chave (Figura 2), que mais foram referenciadas nas teses e dissertações pesquisadas nos últimos dez anos, considerando uma amostra de vinte palavras-chave que se relacionam com outras temáticas do campo da educação e que serão aprofundadas na seção referente à apresentação dos resultados.

Quadro 6 - Trabalhos Coletados / Palavras-chave

\begin{tabular}{|c|c|}
\hline \multicolumn{2}{|c|}{ Palavras-chave mais evidenciadas / incidência: } \\
\hline Evasão & 31 \\
\hline Aprendizagem & 13 \\
\hline EaD & 12 \\
\hline Gestão & 9 \\
\hline Ensino Superior & 5 \\
\hline Tecnologia & 5 \\
\hline Avaliação & 5 \\
\hline Permanência & 4 \\
\hline Retenção & 4 \\
\hline AVA & 3 \\
\hline Formação Docente & 3 \\
\hline Mineração de Dados & 3 \\
\hline Licenciatura & 3 \\
\hline Currículo & 2 \\
\hline Políticas & 2 \\
\hline Qualidade & 2 \\
\hline Comunicação & 2 \\
\hline Estratégias & 2 \\
\hline Autonomia & 2 \\
\hline MOOC & 2 \\
\hline
\end{tabular}

Fonte: Elaborado pelos autores (2019).

Figura 2 - Percentual das palavras-chave

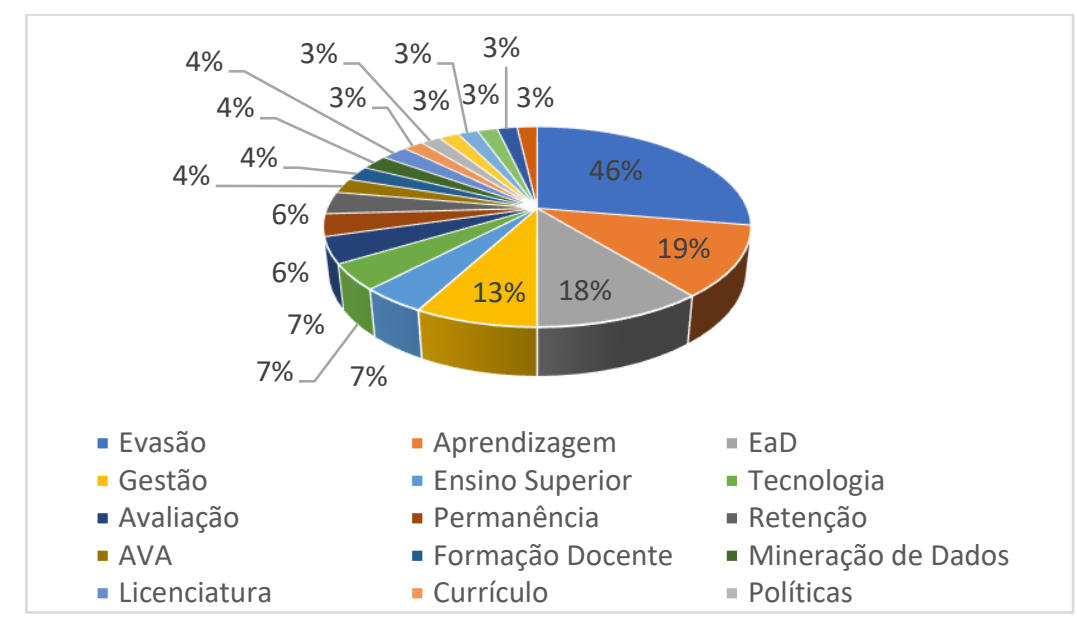

Fonte: Elaborado pelos autores (2019). 


\section{Resultados - (contra)pontos e discussões sobre evasão na EaD}

Aqui descrevemos os resultados e alguns elementos e dimensões que vêm sendo destacados e privilegiados em diferentes produções discentes, com enfoque na evasão em EaD, uma vez que esta temática assume relevância no processo de democratização e consolidação da EaD (FERREIRA, 2002). Diante disso, tecemos interlocuções teóricas e destacamos que os autores serão apresentados conforme as aproximações e distanciamentos sobre a evasão e as questões sociais, políticas e da heterogeneidade de sujeitos relacionadas à EaD. A fim de sintetizar o que será exposto na produção dos dados, foi elaborada uma figura que reúne as principais vertentes e abordagens das pesquisas relacionadas, com o intuito de organizar uma melhor compreensão dos direcionamentos das pesquisas realizadas. Desse modo, a ideia seria de não separar por categorias rígidas de análise, pois os estudos se inter-relacionam e se complementam, em termos de projeções globais das pesquisas na área da evasão na EaD.

\section{Figura 3 - Abordagens das pesquisas}

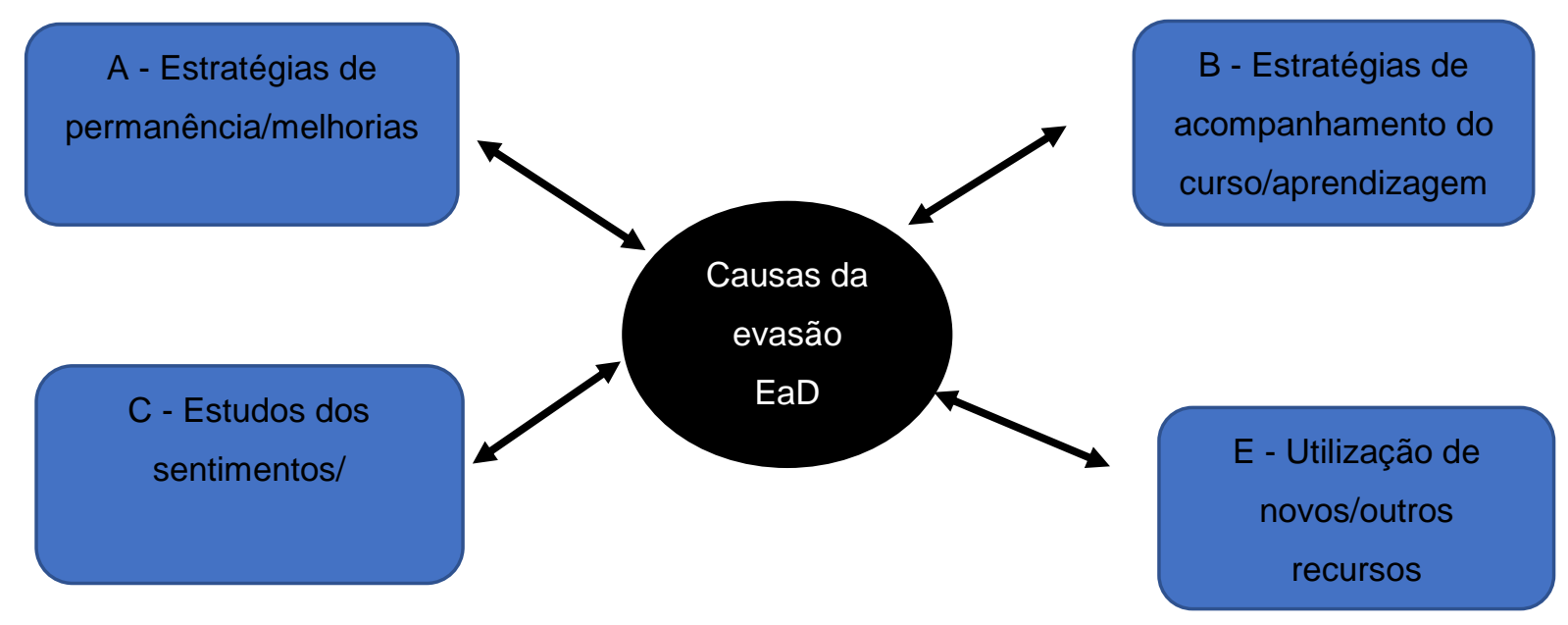

Fonte: Elaborado pelos autores (2019).

Para tanto, a análise e produção de dados segue os seguintes eixos/agrupamentos, com os respectivos autores/ano: A) Estratégias de permanência/melhorias; B) Estratégias de acompanhamento; C) Estudos dos sentimentos/emoções e estilos de aprendizagem; D) Utilização de novos recursos. Cabe esclarecer que as pesquisas dos autores não se restringem a uma única abordagem, visto que os trabalhos se correlacionam e se entrecruzam em diferentes problemáticas de pesquisa. No quadro 7 podemos verificar o agrupamento das abordagens e as respectivas obras produzidas. 


\section{Quadro 7 - Abordagens dos Autores}

\begin{tabular}{|c|c|c|c|}
\hline \multicolumn{4}{|c|}{ Abordagens dos Autores } \\
\hline A) Estratégias de permanência/melhorias & $\begin{array}{l}\text { B) Estratégias de } \\
\text { acompanhamento do } \\
\text { curso/aprendizagem }\end{array}$ & $\begin{array}{l}\text { C) Estudo dos } \\
\text { sentimentos/emoções } \\
\text { e estilos de } \\
\text { aprendizagem }\end{array}$ & $\begin{array}{l}\text { D) Utilização de } \\
\text { novos/outros } \\
\text { recursos }\end{array}$ \\
\hline $\begin{array}{l}\text { Aguiar (2012); Almeida (2007); } \text { Andrade } \\
\text { (2010); Aquino (2016); Araújo (2015); } \\
\text { Bacelos (2017); Bandeira (2012); Bellucci } \\
\text { (2016); Boas (2015); Camponez (2017); } \\
\text { Canarin (2013); Carneiro (2010); Carvalho } \\
\text { (2017); Castro (2017); Dahmer (2013); Diniz } \\
\text { (2013); Napoleão Filho (2013); Fiuza (2012); } \\
\text { Gomes (2017); Gnecco Júnior (2012); } \\
\text { Laguardia (2017); Lott (2017); Martins } \\
\text { (2013); Maurício (2015); Miranda (2012); } \\
\text { Mondini (2017); Monteiro (2016); Moura } \\
\text { (2017); Pacheco (2010); Perez (2014); Petris } \\
\text { (2014); Pino (2017); Pinto Junior (2013); } \\
\text { Radin (2015); Sales (2009); Santos (2013); } \\
\text { Schütz (2010); Silva (2012); Silva (2013); } \\
\text { Silva (2014); Silva (2017);Silva (2017); } \\
\text { Oliveira Sobrinho (2013); Souza (2009); } \\
\text { Tonelli (2011); Umekava (2014). }\end{array}$ & $\begin{array}{c}\text { Antunes (2016); } \\
\text { Cambruzzi (2014); } \\
\text { Coelho (2017); } \\
\text { Gomes (2012); } \\
\text { Kampff (2009); } \\
\text { Portal (2016); } \\
\text { Queiroga (2007); } \\
\text { Silva (2015); } \\
\text { Silva e Silva (2015). }\end{array}$ & $\begin{array}{l}\text { Asfora (2015); } \\
\text { Haas (2015); } \\
\text { Heidrich (2014); } \\
\text { Lemos (2017); } \\
\text { Moraes (2016); } \\
\text { Oliveira (2008); } \\
\text { Oliveira (2013); } \\
\text { Rós (2017). }\end{array}$ & $\begin{array}{c}\text { Marcelino } \\
\text { (2010); } \\
\text { Nascimento } \\
\text { (2016); } \\
\text { Coelho (2017); } \\
\text { Ramos (2011). }\end{array}$ \\
\hline
\end{tabular}

Fonte: Elaborado pelos autores (2019).

Desse modo, sintetizamos no quadro abaixo um resumo das principais causas citadas pelas teses e dissertações rastreadas, bem como os contrapontos apresentados nas investigações em relação às causas de evasão na $\mathrm{EaD}$.

\section{Quadro 8 - Causas x Contrapontos da evasão}

\begin{tabular}{|l|l|}
\hline \multicolumn{1}{|c|}{ Principais Causas } & \multicolumn{1}{|c|}{ Contrapontos } \\
\hline - Falta de letramento digital (desconhecimento das & - Metodologias ativas; \\
plataformas e ferramentas digitais); & - Dimensões emocionais de reconhecimento; \\
- Falta de diálogo com as experiências dos estudantes; & - Pertencimento; \\
- Incomunicação ou comunicação distorcida; & - Ações de gamificação; \\
- Descaso; & - Autonomia; \\
- Falta de acompanhamento do processo de ensino; & - Diálogo e construção cooperativa de conhecimentos, \\
- Ausência de avaliação dos riscos de evasão; & - Políticas educacionais; \\
- Conteúdos pré-programados; & Estratégias de fortalecimento da gestão da \\
- Desqualificação dos tutores; & comunicação; \\
- Precariedade dos polos; & - Fortalecimento da ação pedagógica (qualificação \\
- Figura do tutor forjada na autoinstrução; & profissional), valorização e reconhecimento dos \\
- Pouco investimento em AVA; & professores e tutores; \\
- Rotatividade dos tutores; & - Produção de materiais didáticos de autoria coletiva; \\
- Sobrecarga de trabalho dos estudantes; & - Descentralização e integração dos processos \\
- Falta de preparo dos professores; & acadêmicos; \\
- Falta de identidade do curso; & - Aumento de polos espalhados pelo país; \\
- Falta de escuta sensível por parte da gestão; & - Utilização da EaD em diversas áreas do \\
- Falta de humanização das relações; & conhecimento; \\
- Desconhecimento do perfil do egresso; & - Estratégias metodológicas de ensino; \\
- Grau de hiperculturalidade do curso; & - Acompanhamento das interações; \\
- Ordem de oferta das disciplinas; & - Novos modelos de colaboração; \\
- Preconceitos com a EaD; & - Mudança de convivência; \\
- Confusão entre flexibilidade com facilidade; & - Mapeamento dos sentimentos expressos no AVA; \\
\hline
\end{tabular}


- Reorganização curricular;

- Diversos modelos de tutoria;

- Falta de associação entre teoria e prática;

- Questões econômicas;

- Avaliação;

- Má atuação dos gestores;

- Repetição de práticas tradicionais;

- Falta de qualidade do ensino, informação e serviço prestado;

- Localização dos polos.
- Compreensão dos processos sociais e afetivos;

- Levantamento dos estilos de ensino e aprendizagem;

- Gestão do conhecimento, gestão da evasão e gestão para excelência;

- Estudo dos estilos de aprendizagem;

- Custo do estudante para instituição;

- Geração de alertas de acesso ao AVA;

- Reputação da instituição.

Fonte: Elaborado pelos autores (2019).

Nas produções de dados encontramos alguns problemas recentes da $\mathrm{EaD}$, que passam pelo direito de acesso ao conhecimento e democratização da educação, mas como uma demanda social e, ao mesmo tempo, moeda de troca, que se expande na rede em forma de instrumentalidade e operacionalidade, cujas repercussões socioculturais necessitam de análises políticas, econômicas, sociais, tecnológicas e pedagógicas. Há muitos diagnósticos sobre a evasão na $\mathrm{EaD}$, dentre eles podemos destacar as seguintes tendências: a ausência de contextualização e conteúdos pré-programados, excesso de conteúdos, tarefas e falta de clareza sobre a importância dos professores e tutores manterem um diálogo aberto com os participantes para ouvir e conversar, aproximando e engajando o ensino híbrido do mundo digital com o universo dos estudantes. No cenário da $\mathrm{EaD}$, a discussão criadora, o contato, a interação, a mediação e a intervenção do professor e do tutor, no feedback dado ao estudante, por exemplo, pode ser um fator motivacional para aprender com os outros no movimento formativo de (re)construção de conhecimentos ou a negligência/demora em responder ao outro pode causar o processo de evasão (ABADI, 2014; BOAS, 2015; COELHO, 2017; PINO, 2017).

Além das causas relacionadas às falhas na comunicação, por meio das tecnologias digitais e da própria ausência de uma alfabetização, letramento e inclusão tecnológica, também aparecem como causas a questão financeira e emocional (FIUZA, 2012). Tudo indica que estudar exige dedicação, equilíbrio para se manter em movimento nas pesquisas e metodologias ativas à elaboração coletiva, bem como acolhimento e preparo por parte da instituição quanto aos seus profissionais, para que os estudantes tenham o suporte técnico-pedagógico necessário para o processo formativo e à globalidade humana (UMEKAWA, 2014; SILVA, 2017; NASCIMENTO, 2016). Muitas causas podem ser apontadas para a evasão no ensino a distância, seja por fatores característicos do estudante (habilidade, saberes, desencanto, desinformação), por fatores externos (condições financeiras, saúde, trabalho, família) ou internos a instituição de ensino (currículo, orientação, docentes, estrutura física, suporte técnico, pedagógico e acadêmico). Contudo, a preocupação está no que tem sido feito para 
minimizar essa problemática, que fatores e estratégias de intervenção estão sendo adotadas e desenvolvidas para que o estudante não se sinta abandonado à própria sorte e distante da universidade e da conclusão do seu curso. Será que a condição de ser tratado somente como mais uma matrícula afasta o cursista da possibilidade de ser reconhecido e fazer parte do grupo acadêmico, provocando a evasão? De que forma podemos utilizar as análises sobre a evasão nos cursos de $\mathrm{EaD}$ como forma de aumentar a permanência, o fortalecimento das competências digitais e diferenças, do respeito à diversidade cultural para a participação social? Que estratégias podem ser exploradas para amenizar o fosso entre a inclusão e matrícula nos cursos de $\mathrm{EaD}$ ?

Para Preti (2002, p. 25), “a EaD é, antes de tudo, Educação, é formação humana, é processo interativo de heteroeducação e autoeducação". Segundo o autor, compreender a EaD pela distância é valorizar mais o adjetivo do que a formação do sujeito, destacando que ela não é distante, visto que a EaD não distancia os sujeitos, mas busca aproximá-los no mundo digital. E esse processo não ocorre somente pela inserção de novas tecnologias digitais, mas nas interações humanas, buscando o desenvolvimento de uma rede inclusiva e colaborativa que "é uma das formas de construir conhecimento, requerendo habilidades por parte do professor e do aluno" (SANTOS, 2004, p. 61).

Cabe lembrar que o desenvolvimento da educação, por meio das tecnologias na sociedade global, é algo que precisamos (re)pensar continuamente, pois implica colocar o saber em jogo descentrado, afinal de contas, cada recurso utilizado apresenta uma forma de linguagem e uma visão de mundo (SANTAELLA, 2003). É nessa luta contra o império do método tecnocientífico que expandimos o pensar crítico sobre a evasão, visando combater a passividade e conformismo trazido pelo aparato técnico, que condiciona os sujeitos ao consumismo ingênuo, fabricado e alienante da indústria cultural (ADORNO; HORKHEIMER, 1985). Nesse cenário de contradições formativas gerado pela $\mathrm{EaD}$, percebemos que a relação da educação com a tecnologia ainda é limitante e sofre resistências, preconceitos, carregando muitas fragilidades próprias da desconsideração à cultura do diálogo e aos contextos sociais.

Outro ponto interessante é o sentimento de pertencimento à instituição e ao curso, e o quanto isso interfere no grau de dedicação e motivação para que o estudante prossiga no curso formativo. Nesse viés de pertencimento, aponta-se para a necessidade de mesclar encontros presenciais com atividades a distância, a fim de aproximar os estudantes e melhorar a relação dialógica e o acompanhamento do processo educativo, afinal, o polo não pode ser utilizado apenas para aplicação de provas. Sem sombra de dúvidas, o que mais chamou a atenção foram 
os estudos relacionados aos aspectos sociais e afetivos no ambiente virtual de aprendizagem, como um meio capaz de identificar os estados de ânimo do estudante, considerando as maneiras como a afetividade pode ser reconhecida nas interações no ambiente virtual de aprendizagem, as emoções e sentimentos manifestados no processo de socialização (ASFORA, 2015; HEIDRICH, 2014; LEMOS, 2017; MORAES, 2016; OLIVEIRA, 2008, 2013; RÓS, 2017).

Em outras palavras, é preciso refletir sobre o que está sendo oferecido aos estudantes, pensar inclusive na estrutura dos polos, na acolhida, no material disponibilizado, seja no AVA ou material impresso, propondo revisões constantes, para que os estudantes permaneçam incluídos e com o foco nos estudos. Cabe ainda oportunizar ao estudante uma aprendizagem significativa e que não seja interrompida pela desmotivação devido a questões de gestão de curso ou de polo. Apesar das emoções variarem em termos de intensidade pessoal, é impossível menosprezar a emoção, pois ela é parte da vida e dimensão do ser humano aprendente, relacionada aos valores, gostos, sentidos, jeitos e princípios de cada sujeito. Nessa complexidade das dimensões da emotividade humana há uma relação contínua com as formas do sujeito se expressar, o que pode despertar um novo estado de espírito e a sensação de reconhecimento e pertencimento. Alguns estudos abordados nesse trabalho seguiram essa linha de investigação, já outros buscaram a partir desse conhecimento, propor estilos e estratégias de aprendizagem, de forma mais racionalizada e construtivista - a partir das significações e construções do conhecimento, de modo que no AVA o estudante vivencia experiências sociais e afetivas, que podem ser estimuladas por meio de atividades cooperativas e em redes sociais (ANTUNES, 2016; CAMBRUZZI, 2014; COELHO, 2017; GOMES, 2012; KAMPFF, 2009; PORTAL, 2016; QUEIROGA, 2017; SILVA A., 2015; SILVA J., 2015).

Em relação ao papel do professor/tutor, podemos destacar que este também foi um fator recorrente de evasão, que se dá em diferentes formas de insatisfação por parte dos estudantes: falta de assistência; rotatividade dos tutores; falta de formação específica; desenvolvimento de um trabalho circunscrito ao programado; pouca utilização de ferramentas de interação com os estudantes (AGUIAR, 2012; MOURA, 2017; PACHECO, 2010; DAHMER, 2013; MARTINS, 2013; NAPOLEÃO FILHO, 2013; HAAS, 2015; SALES, 2009). Na verdade, a figura do tutor tanto contribui para a evasão, quanto é um dos fatores que contribui para a permanência do estudante, tendo em vista que o tutor pode ser considerado o elo entre o estudante e a instituição, tendo um importante papel no diálogo interdisciplinar e na aproximação dos processos de ensino articulados com o professor e os colegas de estudo, sendo que o tutor presencial recebeu mais destaque que o tutor a distância nesse processo educativo humanizado. O que nos leva a 
pensar na importância da formação continuada/permanente, para a superação das dificuldades e resistências em relação às tecnologias digitais. O tutor, assim como o professor, deve ser um provocador dessas tensões e desejos empáticos pelo conhecimento, a fim de ajudar o estudante a transformar sua relação com o mundo, na atuação e na prática pedagógica cotidiana (FREIRE, 1996).

\section{Considerações finais}

Dado os altos índices de evasão mapeados nos cursos de EaD, evidenciamos o império de uma lógica voltada para o mercado, com uma preocupação maior de lucro, com o valor econômico advindo das matrículas, do que com as questões ligadas à gestão comunicacional e aos interesses da formação humana, o que deveria ser um processo mútuo de (retro)alimentação e produção do conhecimento empático e solidário. Tal lógica de mercado converge para o domínio de modelos programados, aprisionando os sujeitos a uma forma de pensar e agir ditada e reprodutora de um tecnicismo alienante, pautado na transferência operacional da pedagogia passiva, replicando cursos tradicionais de forma virtualizada. Embora esse mercado privado, solitário e individualista da $\mathrm{EaD}$ apresenta um crescimento, já não basta pensar somente em matrículas, é necessário revisar os processos de ensino propostos pelas instituições para a permanência dos estudantes e melhoria dos processos na $\mathrm{EaD}$, voltando o olhar educativo ao contexto e às necessidades dos estudantes.

A questão da EaD não está somente na democratização do acesso e na ampliação de vagas, mas na qualidade de educação oferecida ao estudante. Por isso, é preciso dar condições de permanência e perspectivas de melhoria nesse campo da educação, para evitar a perpetuação da reprodução, via EaD, de desigualdades sociais e culturais. Podemos considerar que a evolução das pesquisas nesse campo tem sido acompanhada pela problemática da evasão, pelos contrapontos e contradições formativas da EaD no país. As fragilidades e os entraves apontados para o processo educativo estão nos limites da comunicação, na falta de interação humana, de suporte, de feedback, ausência de letramento digital, resistência quanto a mudança de fisicalidade, temporalidade e espacialidade. Uma postura cooperativa exige corresponsabilidade por parte dos envolvidos e implica abertura ao aprender conjunto, no diálogo construído em grupo. Essa perspectiva é um grande desafio para EaD, dada a falta de preparo e experiência dos professores e tutores para lidar com as tecnologias de interação digital. 
Mais do que nunca, precisamos na EaD enfrentar as lacunas e demandas formativas, para trabalhar a interação humana em seu cerne como um processo de descoberta e exploração das tecnologias digitais complexas e variadas, a fim de melhorar a práxis pedagógica e qualificar os discursos nas próprias experiências e horizontes formativos. Assim, com a compreensão realizada a partir de um olhar de distanciamento crítico da amostra dos dados coletados, observamos que o primeiro passo à criação de estratégias consiste em levar em consideração as dificuldades apresentadas pelos estudantes. Então, projetamos que a ação necessária para corrigir os rumos da questão passa pelo levantamento prévio dos conhecimentos e contextos dos estudantes. Tudo indica que as maiores causas da evasão estão nas incomunicações e nos currículos engessados, nas aulas de EaD em forma de monólogos didáticos fixos e predefinidos, unidimensionais e lineares, ou seja, a origem da evasão está em manter a rigidez computadorizada e a visão de aluno como máquina pensante, desconectada das questões sociais e culturais, das formas de vida e dos jogos de linguagem dos estudantes. Por tudo isso, lançamos como uma alternativa possível e viável na educação revigorar o poder da comunicação para combater a evasão na $\mathrm{EaD}$ e minimizar os interesses, econômicos e das mídias que influenciam e se sobrepõe às questões da formação humana nos cursos de EaD. Entende-se como primordial a preocupação com a questão da formação humana em todas as suas dimensões, que vai muito além de uma matrícula e de conteúdos pré-programados, em que a evasão se faz presente e mostra as fragilidades da educação.

\section{Referências}

ABADI, Adejalmo Moreira. Autonomia para Aprendizagem na Educação a Distância: um processo de construção de desafios. 2014. 256f. Dissertação (Mestrado em Ensino de Ciências Exatas) - Universidade do Vale do Taquari, Lajeado, 2014.

ADORNO, Theodor; HORKHEIMER, Max. Dialética do esclarecimento. Rio de Janeiro: Zahar, 1985.

AGUIAR, Wagner Nery Moreira. O ensino a distância da Escola de Gestão Pública do Ceará-EGP como estratégia de formação de servidores públicos: avaliação de resultados. 2012. 131f. Dissertação (Mestrado Profissional em Avaliação de Políticas Públicas) Universidade Federal do Ceará, Ceará, 2012.

ALMEIDA JUNIOR, Antonio Ferreira et al. Parecer CFE no 977/65, aprovado em 3 dez. 1965. Rev. Bras. Educ., Rio de Janeiro, n. 30, p. 162-173, 2005. 
ANDRIOLA, W. B.; ANDRIOLA, C. G.; MOURA, C. P. Opiniões de docentes e de coordenadores acerca do fenômeno da evasão discente dos cursos de graduação da Universidade Federal do Ceará. Ensaio, Rio de Janeiro, v. 14, n. 52, p. 365-382, 2006.

ANTUNES, Oziel Coelho. Um mecanismo para apoiar a análise da interação e do desempenho de alunos em Ambientes Virtuais de Aprendizagem. 2016. 151f. Dissertação (Mestrado em informática) - Universidade Federal do Amazonas, Amazonas, 2016.

ASFORA, Silvia Cauás. fatores condicionantes da relação entre indivíduos e a Iead: hipercultura, atitudes, desempenho e satisfação. 2015. 210f. Tese (Doutorado em Administração) - Universidade Federal de Pernambuco, Recife, 2015.

BAGGI, Cristiane Aparecida dos Santos; LOPES, Doraci Alves. Evasão e avaliação institucional no ensino superior: uma discussão bibliográfica. Avaliação, Campinas, v. 16, n. 2, p. 355-374, 2011. Disponível em: http://doi.org/10.1590/S1414-40772011000200007. Acesso em: 19 mar. 2019.

BEAN, John P.; METZNER, Barbara S. A Conceptual model of nontraditional undergraduate student attrition. Research in Higher Education, USA, v. 12, n. 2, p. 155-187, 1985.

BOAS, Ricardo Rios Villas. Evasão na educação a distância: uma análise conceitual para o apontamento das causas. 2015. 73f. Dissertação (Mestrado em Letras) - Universidade Católica de Pelotas, Pelotas, 2015.

BRASIL. Diplomação, retenção e evasão nos cursos de graduação em instituições de ensino superior públicas. Relatório da comissão especial de estudos sobre evasão nas universidades públicas brasileiras. Brasília: ANDIFES/ABRUEM/SESu/MEC, 1996.

BRASIL. Parâmetros Curriculares Nacionais: introdução aos parâmetros curriculares nacionais. Secretaria de Educação Fundamental. Brasília: MEC/SEF, 1997. Disponível em: http://portal.mec.gov.br/seb/arquivos/pdf/livro01.pdf. Acesso em: 19 mar. 2019.

CABRERA, Lidia; BETHENCOURT, José Tomás; PÉREZ, Pedro Alvarez; AFONSO, Míriam González. El problema del abandono de los estudios universitarios. Relieve, España, v. 12, n. 2, p. 171-203, 2006.

CAMBRUZZI, Wagner Luiz. GVWISE: Uma aplicação de learning analytics para a redução da evasão na educação a distância. 2014. 74f. Dissertação (Mestrado em Computação Aplicada) - Universidade do Vale do Rio dos Sinos, São Leopoldo, 2014.

CARDOSO, Claudete Batista. Efeitos da política de cotas na Universidade de Brasília: uma análise do rendimento e da evasão. 2008. 123p. Dissertação (Mestrado) - Universidade de Brasília, Brasília, 2008.

COELHO, Vinicius Coutinho Guimarães. Análise de logs de interação em ambiente educacional corporativo via mineração de dados educacionais. 2017. 87f. Dissertação (Mestrado em Engenharia Elétrica) - Universidade de Brasília, Brasília, 2017. 
DAHMER, Alessandra Zago. Educação a Distância e Universidade Corporativa: um estudo sobre os sistemas de tutoria dos programas educacionais. 2013. 118f. Tese (Doutorado em Educação) - Pontífica Universidade Católica de São Paulo, São Paulo, 2013.

ETHINGTON, Corinna. A psychological model of student persistence. Research in Higher Education, USA, v. 31, n. 3, p. 279-293, 1990.

FAVERO, Rute Vera Maria. Dialogar ou evadir: Eis a questão! Um estudo sobre a permanência e a evasão na Educação a Distância. 2006. 167 f. Dissertação (Mestrado em Educação) - Universidade Federal do Rio Grande do Sul, Porto Alegre, 2006.

FERREIRA, Norma Sandra de Almeida. As pesquisas denominadas "estado da arte". Educ. Soc., Campinas, v. 23, n. 79, p. 257-272, ago. 2002.

FIUZA, Patricia Jantsch. Adesão e permanência discente na educação a distância: investigação de motivos e análise de preditores sociodemográficos, motivacionais e de personalidade para o desempenho na modalidade. 2012. 145f. Tese (Doutorado em Psicologia) - Universidade Federal do Rio Grande do Sul, Porto Alegre, 2012.

FREIRE, Paulo. Pedagogia da autonomia: saberes necessários à prática educativa. 34. ed. São Paulo: Paz e Terra, 1996.

GAIOSO, Natália Pacheco de Lacerda. O fenômeno da evasão escolar na educação superior no Brasil. 2005. 75p. Dissertação (Mestrado em Educação) - Universidade Católica de Brasília, Brasília, 2005.

GNECCO JÚNIOR, Lenio. Desafios na gestão de cursos EAD: Um estudo de caso nos cursos de Administração a distância da UFSC. 2012. 293f. Dissertação (Mestrado em Administração) - Universidade Federal de Santa Catarina, Florianópolis, 2012.

GOMES, Maria Izabel Lage Martins. Avaliação de um curso de licenciatura em matemática, modalidade a distância, de uma universidade pública. 2012. 147f. Dissertação (Mestrado Profissional em Educação Matemática) - Universidade Federal de Ouro Preto, Ouro Preto, 2012.

HAAS, Daniela Deitos. Contribuições da relação de oposição adjetival para o mapeamento de sentimentos em plataformas online de ensino. 2015. 157f. Dissertação (Mestrado em linguística aplicada) - Universidade do Vale do Rio dos Sinos, São Leopoldo, 2015.

HEIDEGGER, Martin. Ser e tempo. Petrópolis: Vozes, 1995.

HEIDRICH, Leonardo. Diagnóstico do comportamento dos aprendizes na educação a distância com base no estilo de aprendizagem. 2014. 91f. Dissertação (Mestrado em computação aplicada) - Universidade do Vale do Rio dos Sinos, São Leopoldo, 2014.

INSTITUTO NACIONAL DE ESTUDOS E PESQUISAS EDUCACIONAIS ANÍSIO TEIXEIRA - INEP. Censo da Educação Superior. Brasília, DF, 2018. 
KAMPFF, Adriana Justin Cerveira. Mineração de dados educacionais para geração de alertas em ambientes virtuais de aprendizagem como apoio à prática docente. 2009. 186f. Tese (Doutorado em Informática na Educação) - Universidade Federal do Rio Grande do Sul, Porto Alegre, 2009.

KIRA, Luci Frare. A evasão no ensino superior: o caso do curso de Pedagogia da Universidade Estadual de Maringá (1992-1996). 1998. 106p. Dissertação (Mestrado em Educação) - Universidade Metodista de Piracicaba, Piracicaba, 1998.

LEMOS, Lívia Teixeira. Traços de personalidade e persistência discente em cursos de graduação na modalidade a distância. 2017. 145f. Dissertação (Mestrado em Gestão Pública) - Universidade Federal do Espírito Santo, Vitória, 2017.

MARTINS, Carolina Zavadzki. Evasão no curso de graduação em administração na modalidade a distância: um estudo de caso. 2013. 105f. Dissertação (Mestrado em Educação) - Universidade do Oeste, Presidente Prudente, 2013.

MORAES, Raíssa Bárbara Nunes. Estilos de aprendizagem em ações educacionais ofertadas a distância: evidências de validade, validade convergente e análise conceitual. 2016. 164f. Dissertação (Mestrado em Psicologia) - Universidade de São Paulo, Ribeirão Preto, 2016.

MOROSINI, Marília Costa et al. A evasão na Educação Superior no Brasil: uma análise da produção de conhecimento nos periódicos Qualis entre 2000-2011. In: CONFERENCIA LATINOAMERICANA SOBRE EL ABANDONO EN LA EDUCACIÓN SUPERIOR, 1., 2012, Managua, Nicarágua. Anais... Managua, Nicarágua: UNAN, 2012. p. 1-10.

MOURA, Jordana de. Evasão nos cursos de licenciatura em educação a distância: o que dizem os egressos e os evadidos da Universidade Federal de Juiz de Fora. 2017. $103 \mathrm{f}$.

Dissertação (Mestrado em Educação) - Universidade federal de Juiz de Fora, Juiz de Fora, 2017.

NAPOLEÃO FILHO, Jair. Causas para a Evasão dos Alunos do Curso de Graduação a Distância em Ciências Econômicas da Universidade Federal de Santa Catarina. 2013. 215f. Dissertação (Mestrado em Administração) - Universidade Federal de Santa Catarina, Florianópolis, 2013.

NASCIMENTO, Anielton Jose do Nascimento. Uso do processo de avaliação mútua aliado a conceitos de gamificação como suporte ao estudo colaborativo em ambientes de EaD. 2016. 108f. Dissertação (Mestrado em Informática) - Universidade Federal de Paraíba, João Pessoa, 2016.

OLIVEIRA, Eduardo Araújo. i-collaboration: Um modelo de colaboração inteligente personalizada para ambientes de EAD. 2008. 112f. Dissertação (Mestrado em Ciência da Computação) - Universidade Federal de Pernambuco, Recife, 2008.

OLIVEIRA, Eduardo Araújo. i-collaboration 3.0: um framework de apoio ao desenvolvimento de ambientes distribuídos de aprendizagem sensíveis ao contexto. 2013. 158f. Tese (Doutorado em Ciência da Computação) - Universidade Federal de Pernambuco, Recife, 2013. 
OLIVEIRA, Pedro Rodrigues de; OESTERREICH, Silvia Aparecida; ALMEIDA, Vera Luci de. Evasão na Pós-Graduação a Distância: evidências de um estudo no interior do Brasil.

Educ. Pesqui., São Paulo, v. 44, p. 1-20, 2018. Disponível em:

http://www.scielo.br/scielo.php?script=sci_arttext\&pid=S1517-

97022018000100307\&lng=pt\&tlng=pt. Acesso em: 19 mar. 2019.

OLIVEIRA SOBRINHO, José Ferreira de. Evasão na educação superior a distância: estudo de caso no instituto UFC virtual. 2013. 127f. Dissertação (Mestrado Profissional em Políticas Públicas e Gestão da Educação Superior) - Universidade Federal de Ceará, Fortaleza, 2013.

PACHECO, Andressa Sasaki Vasques. Evasão e permanência dos estudantes de um curso de administração do sistema Universidade Aberta do Brasil: uma teoria fundamentada em fatos e na gestão do conhecimento. 2010. 298f. Tese (Doutorado em Engenharia e Gestão do Conhecimento) - Universidade Federal de Santa Catarina, Florianópolis, 2010.

PEIXOTO, Maria do Carmo L.; BRAGA, Mauro Mendes; BOGUTCHI, Tânia F. A evasão no ensino superior brasileiro: o caso da UFMG. Avaliação, Campinas, v. 8, n. 1, p. 161-189, 2003.

PINO, Adriana Soeiro. Educação a distância: propostas pedagógicas e tendências dos cursos de graduação. 2017. 169f. Tese (Doutorado em educação) - Universidade Nove de Julho, São Paulo, 2017.

POLYDORO, Soely Aparecida Jorge. O trancamento de matrícula na trajetória acadêmica no universitário: condições de saída e de retorno à instituição. 2000. 145p. Tese (Doutorado) - Universidade Estadual de Campinas, Campinas, 2000.

PORTAL, Cleber. Estratégias para minimizar a evasão e potencializar a permanência em EAD a partir de sistema que utiliza Mineração de dados educacionais e learning analytics. 2016. 163f. Dissertação (Mestrado em Educação) - Universidade do vale do Rio dos Sinos, São Leopoldo, 2016.

PRETI, Oreste. Fundamentos e políticas em educação a distância. Curitiba: Ibpex, 2002.

QUEIROGA, Emanuel Marques. Geração de modelos de predição para estudantes em risco de evasão em cursos técnicos a distância utilizando técnicas de mineração de dados. 2017. 93f. Dissertação (Mestrado em Computação) - Universidade Federal de Pelotas, Pelotas, 2017.

RÓS, Ariana da. O uso de traços comportamentais na explicação da persistência discente em cursos de licenciatura ofertados na modalidade à distância pela UFES. 2017. 155f. Dissertação (Mestrado em Gestão Pública) - Universidade Federal do Espírito Santo, Vitória, 2017.

SALES, Patrícia de Andrade Oliveira. Evasão em Cursos a Distância: motivos relacionados às características do curso, do aluno e do contexto de estudo. 2009. 176f. Dissertação (Mestrado em psicologia social, do trabalho e das organizações) - Universidade de Brasília, Brasília, 2009. 
SANTAELLA, Lúcia. Cultura das mídias. 3. ed. São Paulo: Experimento, 2003.

SANTOS, Lílian Carmen Lima dos. Educação a distância na formação dos professores. In: MERCADO, Luís Paulo Leopoldo; KULLOK, Maísa Brandão Gomes (org.). Formação de professores: política e profissionalização. Alagoas: Edufal, 2004. p. 35-65.

SANTOS, Elaine Maria dos et al. Evasão na Educação a Distância: identificando causas e propondo estratégias de prevenção. Revista Brasileira de Aprendizagem Aberta e a Distância, São Paulo, p. 1-10, maio 2008.

SILVA, Fernanda Cristina da. Gestão da evasão na EAD: modelo estatístico preditivo para os cursos de graduação a distância da Universidade Federal de Santa Catarina. 2017. 137f. Dissertação (Mestrado em Administração) - Universidade Federal de Santa Catarina, Florianópolis, 2017.

SILVA, Antonio Sergio da. Adequação do modelo de gestão da ISSO 9001 para um núcleo de educação a distância. 2015. 141f. Dissertação (Mestrado em Engenharia de Produção) - Universidade Federal de Itajubá, Itajubá, 2015.

SILVA, Jath da Silva. Uma ferramenta de apoio para a análise de comportamento de estudantes em ambientes virtuais de aprendizagem. 2015. 139f. Dissertação (Mestrado em Informática) - Universidade Federal do Amazonas, Manaus, 2015.

TINTO, Vincent. Dropout from higher education: a theoretical synthesis of recente research. Review of Educational Research, USA, v. 45, n. 1, p. 89-125, 1975.

UMEKAWA, Elienay Eiko Rodrigues. Preditores de fatores relacionados à evasão e à persistência discente em ações educacionais a distância. 2014. 256f. Dissertação (Mestrado em Psicologia) - Universidade de São Paulo, Ribeirão Preto, 2014.

VARGAS, Miramar Ramos Maia. Implantação de Programas de Educação a Distância. Material didático do curso de pós-graduação em educação a distância. Brasília: Universidade de Brasília: Centro de Educação a Distância, 2007. 